\title{
Water and solute absorption from hypotonic glucose-electrolyte solutions in human jejunum
}

\author{
J B Hunt, E J Elliott, P D Fairclough, M L Clark, M J G Farthing
}

\begin{abstract}
While oral rehydration therapy with glucoseelectrolyte solutions is highly effective, the optimal formulation has not yet been defined. Recent clinical studies suggest that stool volume, and thus water losses, may be reduced if glucose is replaced by a polymeric substrate which reduces osmolality. It is possible that the efficacy of glucose monomer based oral rehydration solutions (ORS) will also improve if osmolality is decreased. Using jejunal triple lumen perfusion in healthy adult volunteers net water and solute absorption were studied from three hypotonic solutions with different sodium concentrations $(46,60,75 \mathrm{mmol} / \mathrm{l})$ but identical glucose concentrations ( $90 \mathrm{mmol} / \mathrm{l})$, thus allowing osmolality to rise $(210,240$, and $270 \mathrm{mOsm} / \mathrm{kg}$, respectively). Results from these solutions (ORS 45:210, ORS 60:240, and ORS 75:270) were compared with the World Health Organisation oral rehydration solution (WHO-ORS). Greatest water absorption was seen with ORS 60:240 $(p<0 \cdot 01)$. Sodium absorption from ORS 60:240 and WHO-ORS was similar and greater than sodium absorption from ORS 45:210 $(p<0 \cdot 05)$. Potassium and glucose absorption were greater from ORS 60:240 than from any of the other hypotonic solutions $(p<0.05)$ and were equal to absorption from WHO-ORS). These results in a short segment of healthy human jejunum suggest that hypotonic ORS containing monomeric glucose may increase water absorption.
\end{abstract}

Oral rehydration therapy with glucoseelectrolyte solutions (ORS) is highly effective for the prevention and correction of dehydration, electrolyte imbalance, and acid base disturbance in children and adults with acute infectious diarrhoea of diverse aetiologies. ${ }^{1}$ Although the World Health Organisation oral rehydration solution (WHO-ORS) has had a major impact on morbidity and mortality in the developing world, it is not universally accepted as the ideal ORS for industrialised communities, largely because of its high sodium concentration $(90 \mathrm{mmol} / \mathrm{l}) .^{2}$ In infants and children with non-cholera diarrhoea, stool sodium losses, and thus sodium deficit, are less than in cholera. ${ }^{3}$ Hence, there is a greater requirement for water than sodium absorption in most cases of secretory diarrhoea. Concern about the use of WHO-ORS in the developed world has resulted in the proliferation of ORS with lower sodium concentrations in North America and Europe. This process has largely been led by the pharmaceutical industry. Despite the apparent clinical efficacy of many of these preparations, few have been subjected to controlled clinical evaluation.
During recent years some of the commercially available ORS have been under criticism both because of excessively high concentrations of glucose and other sugars $(>200 \mathrm{mmol} / \mathrm{l})$ and because the sodium content $(35 \mathrm{mmol} / \mathrm{l})$ in some instances is now regarded as being too low for adequate rehydration and replacement of sodium losses. ${ }^{4}$ In addition, until recently all ORS, including WHO-ORS, were hypertonic in respect of human plasma. Thus, although the central role of glucose-sodium cotransport in oral rehydration therapy remains unquestioned, the optimal composition of ORS for the developed world, particularly with regard to sodium and glucose concentrations and osmolality, has not been clearly established. Indeed, the improved clinical efficacy of polymeric substrate ORS, such as those based on rice power, ${ }^{5-7}$ indicate that it is still possible to refine ORS composition and enhance its performance.

In order to select logically new ORS formulations for clinical trial, we and others have developed animal models to determine the key variables in ORS composition. ${ }^{8-12}$ One of the major conclusions from these studies is that osmolality has a dominant role in determining the magnitude of water absorption, with hypotonic ORS apparently producing much greater water absorption than iso- or hypertonic ORS. To determine, firstly, whether the same effect is seen in man and, secondly, whether it may be possible to extrapolate from animals to humans, we have used triple lumen jejunal perfusion of normal volunteers to study water and solute absorption from several hypotonic glucoseelectrolyte solutions and WHO-ORS. Our results indicate that by reducing the concentration of sodium and glucose in WHO-ORS it is possible to increase water absorption.

\section{Methods}

Sixteen healthy volunteers aged between 18 and 47 years were studied. Volunteers gave.written, informed consent and the study protocol was approved by the City and Hackney District Research Ethics Committee. Net jejunal water and solute absorption was measured using a triple lumen perfusion technique. ${ }^{13}$ After an overnight fast the subjects swallowed a triple lumen perfusion tube constructed of polyvinyl chloride tubing, each lumen having an internal diameter of $2.0 \mathrm{~mm}$. The design incorporated a $10 \mathrm{~cm}$ mixing segment and a $30 \mathrm{~cm}$ test segment. The position of the tube was checked by fluoroscopy and once the infusion port was beyond the ligament of Trietz, perfusion was started at a rate of $15 \mathrm{ml} /$ minute using a Watson-Marlow flow inducer, which was calibrated at the start of each study. The proximal samples were aspirated at a 
TABLE I Composition of perfusion solutions

\begin{tabular}{lllll}
\hline \multirow{2}{*}{$\begin{array}{l}\text { Solute } \\
\text { (mmolll })\end{array}$} & \multicolumn{2}{l}{ Solution } & & \\
\cline { 2 - 5 } & $45: 210^{\star}$ & $60: 240^{\star}$ & $75: 270^{\star}$ & WHO-ORS \\
\hline $\mathrm{Na}$ & 45 & 60 & 75 & 90 \\
$\mathrm{~K}$ & 15 & 15 & 15 & 20 \\
$\mathrm{Cl}$ & 37 & 52 & 67 & 60 \\
$\mathrm{HCO}$ & 23 & 23 & 23 & 30 \\
Glucose & 90 & 90 & 90 & 111 \\
$\begin{array}{l}\text { Mean }(\mathrm{SEM}) \text { osmolality } \\
(\mathrm{mOsm} / \mathrm{kg})\end{array}$ & $208 \cdot 4(1 \cdot 5)$ & $235 \cdot 4(1 \cdot 1)$ & $257 \cdot 7(1 \cdot 1)$ & $304 \cdot 4(1 \cdot 7)$ \\
\hline
\end{tabular}

$\star$ Hypotonic solutions are denoted by their sodium concentrations and calculated osmolality, respectively.

TABLE II Mean (SEM) solute concentrations at entry to test segment

\begin{tabular}{|c|c|c|c|c|}
\hline \multirow[b]{2}{*}{ Solute ( $\mathrm{mmol} / \mathrm{l})$} & \multicolumn{4}{|l|}{ Solution } \\
\hline & $45: 210^{\star}$ & $60: 240^{\star}$ & $75: 270^{\star}$ & WHO-ORS \\
\hline $\begin{array}{l}\mathrm{Na} \\
\mathrm{K} \\
\mathrm{Cl} \\
\mathrm{HCO} \\
\text { Glucose } \\
\text { Osmolality }(\mathrm{mOsm} / \mathrm{kg})\end{array}$ & $\begin{array}{l}67 \cdot 1(2 \cdot 1) \\
13 \cdot 7(0 \cdot 3) \\
60(2 \cdot 8) \\
14 \cdot 0(0 \cdot 5) \\
65(1 \cdot 8) \\
223(6 \cdot 1)\end{array}$ & $\begin{array}{l}81 \cdot 6(1 \cdot 5) \\
13 \cdot 4(0 \cdot 2) \\
70(2 \cdot 0) \\
13 \cdot 4(1 \cdot 0) \\
61(3 \cdot 0) \\
241(6 \cdot 7)\end{array}$ & $\begin{array}{l}90 \cdot 9(1 \cdot 5) \\
13 \cdot 3(0 \cdot 2) \\
77(2 \cdot 8) \\
13 \cdot 5(0 \cdot 8) \\
59(3 \cdot 9) \\
251(3 \cdot 8)\end{array}$ & $\begin{array}{l}97 \cdot 1(1 \cdot 2) \\
16 \cdot 5(0 \cdot 2) \\
84(0 \cdot 9) \\
16 \cdot 2(0 \cdot 3) \\
80(3 \cdot 5) \\
281(2 \cdot 4)\end{array}$ \\
\hline
\end{tabular}

${ }^{\star}$ Hypotonic solutions are denoted by their sodium concentrations and calculated osmolality, respectively.

TABLE III Mean (SEM) solute concentrations at exit from the test segment

\begin{tabular}{|c|c|c|c|c|}
\hline \multirow[b]{2}{*}{ Solute $(\mathrm{mmol} / \mathrm{l})$} & \multicolumn{4}{|l|}{ Solution } \\
\hline & $45: 210^{\star}$ & $60: 240^{\star}$ & $75: 270^{\star}$ & WHO-ORS \\
\hline $\begin{array}{l}\mathrm{Na} \\
\mathrm{K} \\
\mathrm{Cl} \\
\mathrm{HCO} \\
\text { Glucose } \\
\text { Osmolality }(\mathrm{mOsm} / \mathrm{kg})\end{array}$ & $\begin{array}{l}89 \cdot 7(5 \cdot 2) \\
13 \cdot 3(0 \cdot 4) \\
77(3 \cdot 8) \\
12 \cdot 3(0 \cdot 7) \\
47(5 \cdot 0) \\
237 \cdot 4(5 \cdot 7)\end{array}$ & $\begin{array}{c}102 \cdot 7(5 \cdot 0) \\
12 \cdot 6(0 \cdot 4) \\
87(4 \cdot 0) \\
12 \cdot 5(1 \cdot 8) \\
38(5 \cdot 4) \\
252 \cdot 5(5 \cdot 6)\end{array}$ & $\begin{array}{c}103 \cdot 3(3 \cdot 4) \\
12 \cdot 3(0 \cdot 4) \\
88(4 \cdot 4) \\
11 \cdot 7(0 \cdot 9) \\
42(4 \cdot 7) \\
257 \cdot 1(5 \cdot 9)\end{array}$ & $\begin{array}{c}105 \cdot 5(1 \cdot 3) \\
14 \cdot 9(0 \cdot 2) \\
90(1 \cdot 3) \\
15 \cdot 1(0 \cdot 3) \\
57(3 \cdot 8) \\
277 \cdot 6(3 \cdot 3)\end{array}$ \\
\hline
\end{tabular}

^Hypotonic solutions are denoted by their sudium concentrations and calculated osmolality, respectively.
$90 \mathrm{mmol} / \mathrm{l}$. This is slightly lower than in WHOORS $(111 \mathrm{mmol} / \mathrm{l})$. This reduction in glucose decreased the osmolality but did not reduce the glucose concentration in the test segment below that known to stimulate maximally water absorption in healthy intestine. ${ }^{15}$ The sodium concentration in the three test solutions was 45,60 , and $75 \mathrm{mmol} / \mathrm{l}$ and consequently the calculated osmolality increased para passu $(210,240$, and $270 \mathrm{mOsm} / \mathrm{kg}$ ). This range of sodium concentrations was chosen to produce solutions with lower sodium contents than WHO-ORS and to explore the possible effect of changing the ratio of sodium to glucose, as a ratio of $1: 2$ has previously been reported to be optimal for stimulating sodium and water absorption in an animal model. ${ }^{12}$ The range included sodium concentrations similar to those that have been shown to be the minimum necessary to promote sodium absorption from hypotonic solutions in normal human jejunum. ${ }^{16}$ Thus, the design of these solutions allowed us not only to compare the relative efficacy of hypotonic ORS and WHO-ORS in promoting water and solute absorption, but also to examine the importance of the interplay between the sodium concentration and osmolality.

All solutions were warmed in a water bath to $37^{\circ} \mathrm{C}$ and gassed with $95 \% \mathrm{O}_{2}$ and $5 \% \mathrm{CO}_{2}$ at a rate of $5 \mathrm{l} /$ minute for 30 minutes before and during the perfusion. A total of $2 \mu \mathrm{Ci} / 1\left[{ }^{14} \mathrm{C}\right] \mathrm{PEG}$ (Amersham International) with a $2.5 \mathrm{~g} / \mathrm{l}$ PEG (molecular weight 4000 ) were added as a volume marker to all solutions. ${ }^{17} \mathrm{Al}$ reagents were Analar-R grade supplied by British Drug Houses Chemicals Ltd, Poole, England.

\section{ANALYSIS OF SOLUTIONS}

The PEG content of the samples was determined in triplicate by scintillation spectroscopy using an LKB Wallac 1210 ultrabeta scintillation counter. This was programmed to correct for quenching of activity produced by bile contamination of the samples. A quench curve was constructed using $\left[{ }^{14} \mathrm{C}\right]$ seed pellets of known activity (LKB Wallac) mixed with serial dilutions of human bile and scintillation fluid (Optiphase Safe, Fisons Pharmaceuticals). A total of $0.4 \mathrm{ml}$ of perfusate was counted in $4.6 \mathrm{ml}$ of scintillation cocktail. Sodium and potassium concentrations were analysed by flame photometry (Instrumentation Laboratory, 934). Total $\mathrm{CO}_{2}$ was determined immediately using a Corning $965 \mathrm{CO}_{2}$ analyser and chloride by Chemlab (CCM1) chloride meter. The glucose concentration was determined within two hours with a Beckman glucose analyser 2. Osmolality was measured by the vapour pressure technique using a Westcor 5500 vapour pressure osmometer. Net movement of water and solute was calculated using standard formulae.$^{13}$ Results are expressed as mean (SEM). Statistical analysis was by analysis of variance and progression to Student's $t$ test if indicated.

The composition of the solutions tested is shown in Table I. The concentrations of the major constituents of ORS, glucose and sodium, were manipulated to ensure hypotonicity of the test solutions. The glucose concentration was kept constant in the three experimental ORS at

\section{Results}

The composition and osmolality of all the solutions changed over the mixing segment (Table II). This effect was most noticeable in solutions 


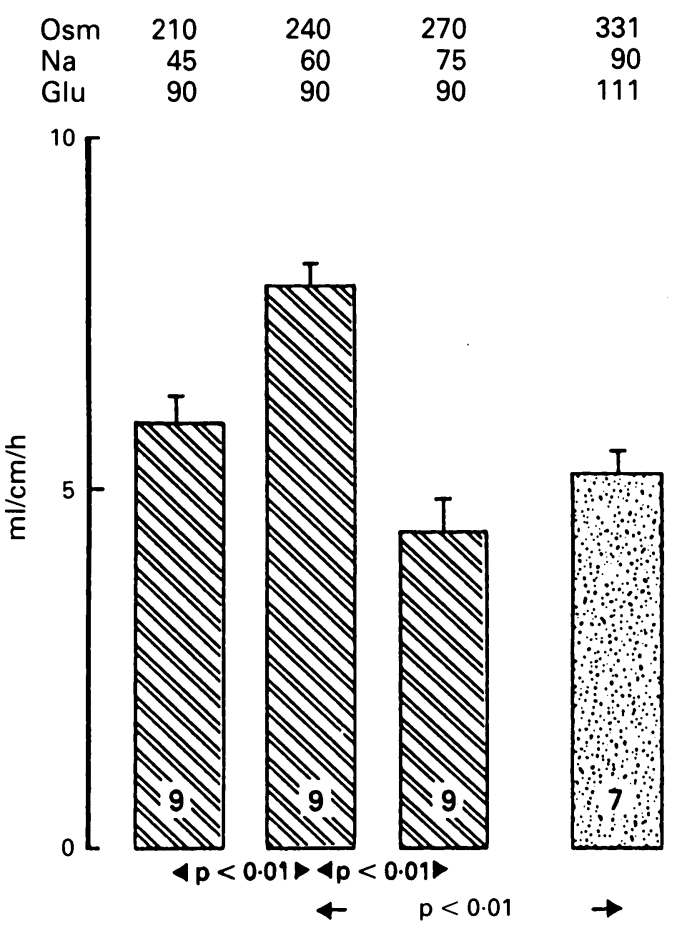

Figure 1: Net water absorption from oral rehydration solutions (ORS) 45:210, 60:240, 75:270 and WHO-ORS in $30 \mathrm{~cm}$ triple lumen perfusion system. ORS 45:210, $60: 240$, and 75:270 were perfused in nine subjects. WHO-ORS was perfused in seven different subjects on a separate occasion. ORS 60:240 promoted greater net water absorption than either of the other two hypotonic solutions or WHO-ORS $(p<0.01)$. Results are expressed as mean (SEM).

with low initial sodium concentrations. The sodium concentration of ORS 45:210 and 60:240 increased by approximately $20 \mathrm{mmol} / 1$ whereas the increment in WHO-ORS and ORS 75:270 was less. The changes in chloride concentration paralleled those of sodium concentration. Similar reductions of approximately $30 \mathrm{mmol} / \mathrm{l}$ were seen in the glucose concentrations of all four solutions. The bicarbonate content of the three hypotonic solutions decreased by a third, while that of the WHO-ORS fell by almost half. As a result of these changes in solute composition, the osmolality of three of the four solutions changed, with an increase in osmolality of ORS 45:210 and a decrease in osmolality of both ORS 75:270 and WHO-ORS. The osmolality of ORS 60:240 was unchanged.

Similar changes occurred over the test segment (Table III). The sodium concentration rose in all solutions but was greatest for ORS 45:210 $(22.6 \mathrm{mmol} / \mathrm{l})$ and least for WHO-ORS (8.6 mmol/l). Chloride changes occurred in parallel with sodium changes. Glucose concentrations decreased by $23 \mathrm{mmol} / \mathrm{l}$ in both ORS 60:240 and WHO-ORS. Decrements of $18 \mathrm{mmol} / \mathrm{l}$ and 17 $\mathrm{mmol} / \mathrm{l}$ were seen with ORS $45: 210$ and ORS 75:270. Only slight and similar decreases in bicarbonate concentrations were seen with all solutions.

The hypotonic solution with a sodium concentration of $60 \mathrm{mmol} / \mathrm{l}$ and osmolality of 240 $\mathrm{mOsm} / \mathrm{kg}$ (ORS 60:240) promoted greater net water absorption than either of the other hypotonic solutions or WHO-ORS $(\mathrm{p}<0.01)$. Net water absorptions from ORS 45:210, 75:270, and WHO-ORS were similar (Fig 1).
Net sodium absorption from both ORS 60:240 and WHO-ORS was greater than from ORS 45:210 ( $<<0.01)$ but not different from that of ORS 75:270 (Fig 2). The results for net glucose absorption (Fig 3) were congruent with those for water. Equal net glucose absorption occurred with ORS 60:240 and WHO-ORS, and was greater than with ORS 45:210 and ORS 75:270 $(\mathrm{p}<0.05)$.

Net potassium absorption was similar for both ORS 60:240 (125 (9.4) and WHO-ORS (122.6 $(11.4) \mu \mathrm{mol} / \mathrm{cm} / \mathrm{hour}$ ) and was significantly greater than for either of the other two hypotonic solutions (ORS 45:210, 85.0 (10.5) and 75:270, $68.6(14.5) \mu \mathrm{mol} / \mathrm{cm} /$ hour$)$. Net bicarbonate absorption for the WHO-ORS (109.7 (11.7) $\mu \mathrm{mol} / \mathrm{cm} /$ hour) was similar to that for ORS $45: 210,60: 240$, and $75: 270(110 \cdot 2(14 \cdot 1), 123 \cdot 8$ $(17 \cdot 7)$, and $74.8(26 \cdot 4) \mu \mathrm{mol} / \mathrm{cm} /$ hour, respectively).

\section{Discussion}

The greatest water absorption was seen with ORS 60:240. This was significantly more than for all other solutions tested $(p<0.01)$. At the point of entry into the test segment, the WHOORS contained the highest concentration of both glucose and bicarbonate, both of which stimulate sodium and water absorption in the normal jejunum $^{18-21}$ and might have been expected to stimulate active transport more than the hypotonic ORS and therefore to have produced greatest water absorption. However, it is unlikely that the differences in water absorption relate to the concentrations of sodium, glucose, or bicarbonate. A maximal stimulatory effect on

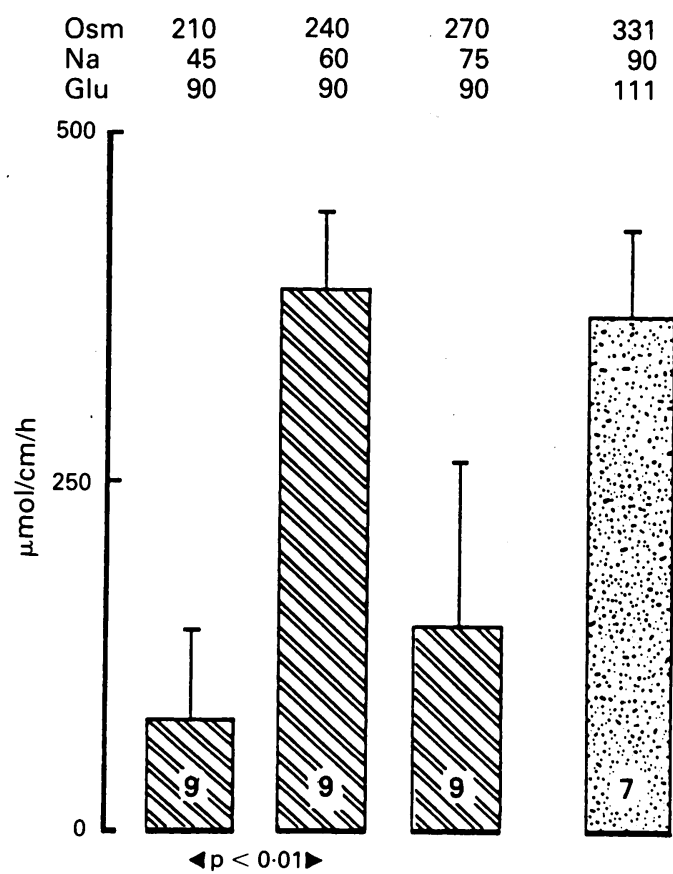

Figure 2: Net sodium absorption from oral rehydration solutions (ORS) 45:210, 60:240, 75:270 and WHO-ORS in a $30 \mathrm{~cm}$ triple lumen perfusion system. ORS 45:210, 60:240, and 75:270 were perfused in nine subjects. WHO-ORS was perfused in seven different subjects on a separate occasion. ORS 60:240 promoted greater net sodium absorption than 45:210 $(p<0 \cdot 01)$. Net sodium absorption absorption than $45: 210(p<0 \cdot 01)$. Net sodium absorption
from $O R S$ 75:270 and WHO-ORS was similar to that from ORS 60:240. Results are expressed as mean (SEM). 


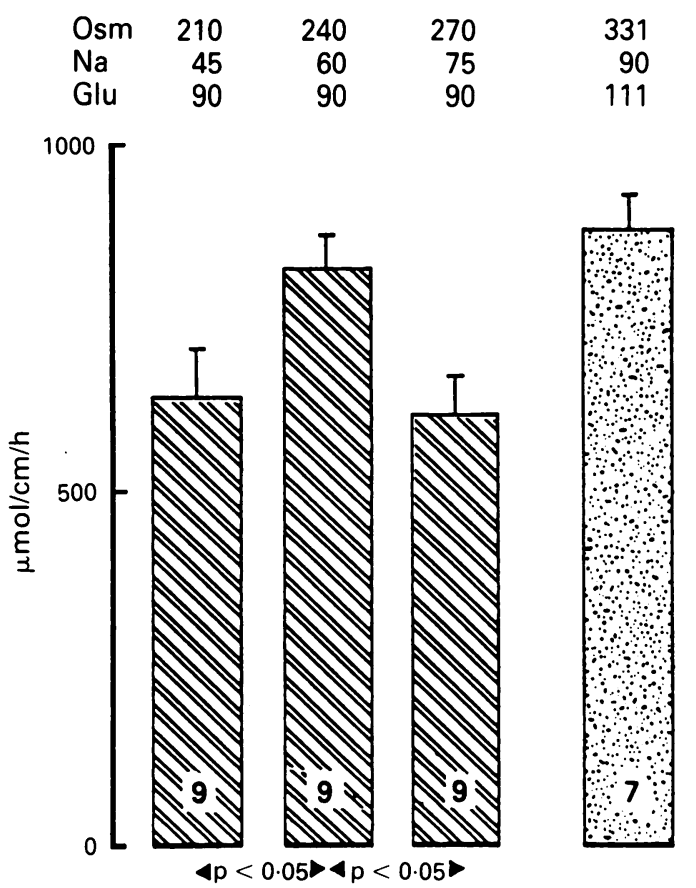

Figure 3: Net glucose absorption from oral rehydration solutions (ORS ) 45:210, 60:240, 75:270, and WHO-ORS in a $30 \mathrm{~cm}$ triple lumen perfusion system. ORS 45:210, $60: 240$, and 75:270 were perfused in nine subjects. WHO$O R S$ was perfused in seven different subjects on a separate occasion. Net glucose absorption from ORS 60:240 and WHO-ORS was similar and greater than absorption from either of the two other ORS $(p<0.05)$.

water absorption has been found with glucose concentrations of $56 \mathrm{mmol} / 1,{ }^{15}$ and concentrations as low as $30 \mathrm{mmol} / \mathrm{l}$ have been suggested to be ideal for the promotion of sodium absorption in short segments of normal intestine. ${ }^{18}$ The concentration of glucose in all solutions at exit from the test segment was above this concentration. Similarly, sodium restriction in perfusion fluids does not limit glucose absorption in the jejunum. ${ }^{22}$

Net sodium absorption in the jejunum is mainly the result of passive processes and is greatly influenced by solvent drag. ${ }^{20}$ Sodium absorption from isotonic solutions containing glucose polymers is dependent upon the sodium concentration, net absorption only occurring when the concentration is above $80-90 \mathrm{mmol} / 1 .{ }^{16}$ Below this value the rate of sodium entry into the jejunum down the concentration gradient seems to exceed the rate of exit by both active and passive processes. The gradient for sodium entry into the jejunum in the hypotonic solutions was increased by restricting the sodium concentration, and thus there was a risk of inducing sodium secretion. In spite of this, no differences in sodium absorption from ORS 60:240 and WHO-ORS were observed. Any increase in diffusion of sodium into the jejunum down the concentration gradient with ORS 60:240 must have been offset by the influence of solvent drag on sodium absorption caused by the increased passive absorption of water seen with this solution.

Potassium absorption is thought to occur as a passive process determined by the electrochemical gradient across the cell membrane. ${ }^{23}$ Thus, increased absorption would be expected from isotonic solutions with higher potassium con- centrations. Our results show equal potassium absorption from both ORS 60:240 and WHOORS despite the $20 \%$ greater potassium concentration of WHO-ORS at entry to the test segment. Similarly, potassium absorption was greater from ORS 60:240 than from either of the other two hypotonic solutions in spite of the fact that they all had the same potassium concentration. These differences in potassium absorption can only be explained by the effect of solvent drag. Electrogenic sodium absorption results in the accumulation of positive charge at the brush border, which inhibits potassium absorption. ${ }^{18}$ The presence of increased potassium absorption from ORS 60:240 compared with the other hypotonic ORS suggests that active sodium absorption from the three hypotonic ORS was similar.

Absorption of glucose from the hypotonic ORS paralleled water absorption. Glucose absorption from ORS 60:240 and WHO-ORS was the same despite the higher glucose concentration in WHO-ORS at entry to the test segment (Table II). The mechanisms by which glucose is absorbed by the human jejunum remain controversial. Some workers have shown saturation kinetics of glucose absorption ${ }^{24}$ suggesting only active transport of this substance, while others have shown passive absorption as well. ${ }^{25}$ The presence of passive glucose absorption has recently been shown in human tissue in vitro. ${ }^{26}$ Work in an animal model perfusion system has led Pappenheimer and Reiss ${ }^{27}$ to suggest there is considerable passive absorption of glucose once active electrogenic sodium absorption has been stimulated. Our results are consistent with increased passive absorption of glucose from ORS 60:240 by the effect of solvent drag.

It is well recognised that glucose can promote sodium absorption from hypertonic solutions against an osmotic gradient. ${ }^{20}$ It is also known that in man water absorption and osmolality are inversely related in solutions with osmolalities of $250 \mathrm{mOsm} / \mathrm{kg}$ or greater ${ }^{20}$ but below this osmolality the relation has been found to break down. ${ }^{28}$ Sodium absorption from ORS 60:240 and 75:270 was not adversely affected in the test segment, although total sodium absorption throughout the entire intestine was probably less for the hypotonic solutions than for WHO-ORS.

ORS 45:210 was of a lower osmolality than ORS 60:240, both initially and at entry to the test segment. It would have been expected to have promoted greatest passive water absorption. However, there will have been greater entry of sodium into the lumen with ORS 45:210 than with $60: 240$ because of the greater sodium gradient. During perfusion studies there is considerable bidirectional flux of water and solute, ${ }^{28}{ }^{29}$ and water secretion as a consequence of sodium entry into the lumen will have offset water absorption caused by the osmotic gradient.

This study shows that it is possible, in a $30 \mathrm{~cm}$ test segment of normal human jejunum, to increase water absorption from ORS above that seen with the WHO-ORS. This was achieved by restricting both sodium and glucose concentrations, to ensure hypotonicity of the solutions. At the same time sodium absorption in the test segment was not adversely affected. Caution 
must be exercised in extrapolating from these findings in a short segment of healthy adult jejunum to possible effects in the whole bowel of children and adults with diarrhoeal illnesses. During secretory diarrhoea, water and sodium entering the intestine will dilute any ORS consumed and the solute concentrations achieved will differ from those reported here. Similarly, we do not know how far distally ORS progresses and have only very limited data as to the overall efficacy of the bowel for absorption of solute in diarrhoeal states. However, the jejunum is highly permeable and the ileum less so. ${ }^{3031}$ Hypotonic solutions may promote increased water and solute absorption in the jejunum when compared with their isotonic or hypertonic counterparts. While glucose has not been shown to stimulate net sodium absorption in healthy human ileum, it has been shown to increase electrogenic sodium absorption in perfusion studies, to increase ileal sodium and water absorption in vivo during secretion in dogs, ${ }^{32}$ and to increase water and sodium absorption from secretory human ileal tissue studied in vitro. ${ }^{33}$ One advantage of hypotonic solutions is that they may offer 'free' water absorption in the jejunum and allow solute stimulated absorption in the ileum. The concentration of solutes is important as it is known that in children with acute diarrhoea, oral rehydration treatment may lead to the appearance of reducing substances in the stool, ${ }^{44}$ particularly when glucose absorption is impaired as in rotavirus diarrhoea. ${ }^{35}$ The persistence of osmotically active glucose, or its metabolic products, in the colon may decrease salvage of water and thus ORS with high glucose concentrations may paradoxically increase stool water loss. ${ }^{4}$ Reducing glucose concentration too drastically will, when the entire small intestine is considered, ultimately impair efficacy. However, glucose concentrations at the end of the test segment in the present study were $38-47 \mathrm{mmol} / \mathrm{l}$ indicating that there would still be adequate substrate present in the proximal jejunum for further active and water absorption.

These findings suggest that greater water and solute absorption can be promoted by reducing the osmolality of ORS and that hypotonicity may be achieved by reducing glucose, sodium, and potassium concentrations, manoeuvres which would not seem to hazard the correction of electrolyte imbalance. Use of ORS 60:240 might result in the faster correction of dehydration and thus decrease the total requirement for ORS. This reduction should negate the risks of hypernatraemia which is sometimes seen when WHOORS is used, particularly when free water is not also administered during the maintenance phase of the rehydration process. We are encouraged by these findings and propose to test the merits of a hypotonic solution such as ORS 60:240 in a double blind controlled clinical trial.

1 Nalin DR, Levine MM, Mata LJ, De Cespedes C, Vargas W, Lizano C, et al. Oral rehydration and maintenance of children with rotavirus and bacterial diarrhoeas. Bull World Health Organ 1979; 57: 453-9.

2 Tripp JH, Harries JT. UNICEF/WHO glucose electrolyte solution not always appropriate. Lancet 1980; ii: 793.

3 Molla MA, Rahman M, Sarker SA, Sack DA, Molla A. Stool electrolyte content and purging rates in diarrhoea caused by
rotavirus enterotoxigenic $E$ coli and $V$ cholerae in children. $\mathcal{F}$ Pediatr 1981; 98: 835-8.
4 Meeuwisse GW. High sugar worse than high sodium in oral rehydration solutions. Acta Paediatr Scand 1983; 72: 161-6.

5 Carpenter CCJ, Greenough WB, Pierce NF. Oral rehydration therapy: The role of polymeric substrates. $N E n g l \mathcal{F} \mathrm{Med}$ 1988; 319: 1346-8.

6 Molla AM, Sarkar SA, Hassain M, Molla A, Greenough WB III. Rice powder electrolyte solution as oral therapy in diarrhoea due to Vibrio cholerae and Escherichia coli. Lancet 1982; i: 1317-9.

7 Patra FC, Mahalanabis D, Jalan KN, Sen A, Banerjee P. Is oral rice electrolyte solution superior to glucose electrolyte solution in infantile diarrhoea? Arch Dis Child 1982; 57 910-2.

8 Patra FC, Mahalanabis D, Jalan KN. Stimulation of sodium and water absorption by sucrose in the rat small intestine Acta Paediatr Scand 1982; 71 : 103-7.

9 Rolston DDK, Borodo MM, Kelly MJ, Dawson AM, Farthing MJG. Efficacy of oral rehydration solutions in a rat model of secretory diarrhea. F Pediatr Gastroenterol Nutr 1987; 6: 624 30.

10 Lifshitz F, Wapnir RA. Oral rehydration solutions: experimental optimization of water and sodium absorption. f Pediatr 1985; 106: 383-9.

11 Salim AFM, Walker-Smith JA, Farthing MJG. Experimental rat rotavirus infection: a new animal model for studying efficacy of oral rehydration solutions (ORS). Gut 1988; 29: A1476.

12 Wapnir RA, Lifshitz F. Osmolality and solute concentration their relationship with oral rehydration solution effectiveness: An experimental assessment. Pediatr Res 1985; 19 894-8.

13 Cooper H, Levitan R, Fordtran JS, Ingelfinger FJ. A method for studying absorption of water and solute from the human small intestine. Gastroenterology 1966; 50: 1-7.

14 Barclay GR, Turnberg LA. Effect of cold-induced pain on salt and water transport in the human jejunum. Gastroenterology 1988; 94: 994-8.

15 Sladen GE, Dawson AM. Interrelationships between the absorption of glucose, sodium and water by the normal human jejunum. Clin Sci 1969; 36: 119-32.

16 Spiller RC, Jones BJM, Silk DBA. Jejunal water and electrolyte absorption from two proprietary enteral feeds in man lyte absorption from two proprietary enteral feeds in man

17 Wingate DL, Sandberg RJ, Phillips SF. A comparison of stable and $\left[{ }^{14} \mathrm{C}\right]$-labelled polyethylene glycol as volume stable and $\left[{ }^{4} \mathrm{C}\right]-l a b e l l e d$
indicators in the human jejunum. Gut 1972;13: 812-5.

18 Fordtran JS. Stimulation of active and passive sodium absorption by sugars in the human jejunum. F Clin Invest 1974; 55 728-37.

19 Modigliani R, Bernier JJ. Absorption of glucose, sodium and water by the human jejunum studied by intestinal perfusion with a proximal occluding balloon and at variable flow rates. Gut 1971; 12: 184-93.

20 Fordtran JS, Rector FC, Carter NW. The mechanism of sodium absorption in the human small intestine. $7 \mathrm{Clin}$ Invest 1968; 47: 884-900.

21 Sladen GE, Dawson AM. Effect of bicarbonate on sodium absorption by the human jejunum. Nature 1968; 218: 267-8.

22 Saltzman D, Rector FC, Fordtran JS. The role of intraluminal sodium in glucose absorption in vivo. $\mathcal{F}$ Clin Invest 1972; 51 : 876-85.

23 Turnberg LA. Potassium transport in the human small bowel. Gut 1971; 12: 811-8.

24 Holdsworth DC, Dawson AM. The absorption of monosaccharides in man. Clin Sci 1964; 27: 371-9.

25 Read NW, Holdsworth CD, Levin RJ. Electrical measurement of intestinal absorption of glucose in man. Lancet 1974 ii: 624-7.

26 Dawson DJ, Burrows PC, Lobley RW, Holmes R. The kinetics of monosaccharide absorption by human jejunum biopsies: evidence for active and passive processes. Digestion 1987; 38: 124.

27 Pappenheimer JR, Reiss KZ. Contribution of solvent drag through intercellular junctions to absorption of nutrients by through intercellular junctions to absorption of nutrients by
the small intestine of the rat. $\mathcal{~ M e m b r ~ B i o l ~ 1 9 8 7 ; ~ 1 0 0 : ~ 1 2 3 - ~}$ 36 .

28 Soergel KH, Whalen GE, Harris JA. Passive movement of water and sodium across the human small intestinal mucosa. water and sodium across the hu

29 Hindle W, Code CF. Some differences between duodenal and ileal absorption. Am f Physiol 1962; 203: 215-20.

30 Fordtran JS, Rector FC, Ewton FM, Soter N, Kinney J. Permeability characteristics of the human small intestine. $\mathcal{f}$ Clin Invest 1965; 44: 1935-44.

31 Davies GR, Santa-Ana CA, Morawski SG, Fordtran JS Permeability characteristics of human jejunum, ileum, proximal colon and distal colon: results of potential difference measurements and unidirectional fluxes. Gastroenterology 1982; 83: 844-50.

32 Carpenter CCJ, Sack RB, Feeley JC, Steenberg RW. Site and characteristics of electrolyte loss and effect of intraluminal glucose in experimental canine cholera. $\mathcal{F}$ Clin Invest 1968 ; 47: 1210-20.

33 Al Awaqti Q, Cameron JL, Greenough WB III. Electrolyte transport in human ileum: Effect of purified cholera exotransport in human ileum: Effect of puri
toxin. Am $\mathcal{F}$ Physiol 1973; 224: 818-23.

34 Elliott EJ, Da Cunha Ferreira RMC, Cameron D, Farthing MJG, Walker-Smith JA. Evaluation of three oral rehydration solutions designed for use in developed countries. Aliment Pharmacol Therap 1989; 3: 233-43.

35 Graham DY, Sackman JW, Estes MK. Pathogenesis of rotavirus induced diarrhea. Preliminary studies in miniature swine piglets. Dig Dis Sci 1984; 29: 1028-35. 